\title{
Kleinere morphologische Mittheilungen.
}

\section{Von \\ A. Winkler.}

Trifulium procumbens L. (T. agrarium Poll.) Als wesentliches Kennzeichen geben die Floren an, dass das mittlere Blättchen länger gestielt sei, als die beiden seitenständigen. Diese Angabe ist indessen nicht ganz genau. So lange die Pflanze keine Blüthentriebe macht, — an den Wurzel-Rosetten - sind die drei Blättchen gleich lang gestielt. Erst an der Basis der Blüthen-Achsen verlängert sich der Stiel des mittleren ein wenig, ound nur die an den gestreckten, blüthentragenden Achsen stehenden Blätter haben ein länger gestieltes Mittel-Blättchen.

Bekannt ist, dass der Same der Leguminosen - mit Ausnahme der zu den Culturgewächsen gehörigen - oft mehrere Jahre in der Erde liegt, bevor er keimt.

Ein auffallendes Beispiel bot mir in dieser Beziehung Vicia Cracca L., von welcher ich im Jahre 1867 Samen gesammelt und im Frühjahre 1868 in einem Topf gesät hatte. Da der Same bis zum Herbste nicht aufgegangen war, stellte ich den Topf den Winter über zurück und zog im Sommer 1869 eine andere Pflanze darin. Ebenso in den beiden nächsten Sommern 1870 und 1871. Den Samen der Vicia hielt ich für abgestorben, obgleich ab und zu einige Körner an die Oberfläche gekommen waren, welche sich vollkommen hart anfühlten, und welche ich daher wieder in die Erde steckte. Im Winter 1871/72 hatte ich ein Paar Exemplare der Capsella rubella Reuter in demselben Topfe gehalten und sah zu meiner Verwunderung im Frühjahre 1872 fast sämmtliche Körner der Vicia Cracca aufgehen. Ihre weitere Entwickelung war auch eine vollkommen normale. Die Haupt-Achse starb - 
wie fast bei allen Vicieen - ab, und es entwickelten sich an ihrer Stelle die Seiten-Sprosse.

Aber im Frühjahre 1874 - also nach sechs Jahren kamen noch zwei Körner zur Keimung, und diese zeigten die eigenthümliche Erscheinung, dass sich gerade bei ihnen die Haupt-Achse entwickelte, während die Seiten-Sprosse kaum zwei Blattpaare hervorbrachten und dann stehen blieben oder ganz abstarben.

Ich würde annehmen, dass die seit dem Frühjahre 1871 in dem Topfe unterhaltene Feuchtigkeit die Keimung im Jahre 1872 verursacht hätte, wenn nicht der Keimung von 1874 wiederum zwei Winter vorangegangen wären, in denen der benutzte Topf kalt und trocken gestanden hatte.

Phaseolus, In der botan. Zeitg. 18こ̃2, Spalte 73ॅ. giebt C. Bouché unter Anderem an, dass sich die Keimblätter des $P h$. mulıiflorus Lmk. dicht über der Erde ausbreiten, diejenigen des $P$ h. vulgaris L. 2-3 Zoll über die Erde erheben.

Rossmässler bildet den Ph. multifurus W. in: "der Wald", Taf. XIX, 1863, als hypogäisch keimend ab.

Wiederholte Aussaat-Versuche haben nun ergeben, dass die Cotyledonen des Ph. multiflorus wirklich nicht über den Erdboden treten, mögen die Samen tief oder flach gelegt werden. (Vgl. Sitzungsber. 25. Febr. 1876 S. 42, 43.)

Phaseolus bietet also ein Analogon zu Rhammus, dessen eine Species (Frangula L.) unterirdisch keimt, die übrigen oberirdisch.

Aber Ph. vulgaris L. stellt doch, obgleich seine Kotyledonen weit über den Erdboden treten, nur einen Uebergang zu den hypogäisch keimenden Pfianzen dar, weil die Kotyledonen sich nur ausdehnen und ergrünen, ohne indessen eigentlich laubartig zu werden. Sie bleiben fleischige Klumpen ohne Gefässbündel.

Eine andere Art des Ueberganges zeigt Acer dasycarpum Ehrh., dessen Kotyledonen bald unter der Erde bleiben, bald sich mehr oder weniger über die Oberfläche derselben erheben. Eine Umwandlung in laubige Blätter - wie bei den übrigen Acer-Arten - findet auch bier nicht statt. 
In der Sitzung der Gesellschaft naturforschender Freundo vom 19. April 1870. (Bot. Ztg. 1870 Spalte 438.) hat A. Braun sieben Species der Gattung Linaria (arvensss, triphylla, vulgaris, striata, minor, alpina und supina) angeführt, bei welchen sich hypokotyle Sprossen bilden.

Diesen kann ich zwei neue hinzufügen, $L$. simplex D.C. und L. genistifolia Mill.

Iinaria genistifolia scheint vorzugsweise die Eigenschaft zu besitzen, dass sich diese Sprosse auf Kosten der HauptAchse ausbilden. Wenigstens fand ich bei einer Reihe von 30-40 Exemplaren nur eines, an welchem die letztere, unter Verkümmerung der Seitensprosse, zur vollen Entwickelung gelangt war. Bei allen übrigen hatte es der Haupt-Trieb nur bis auf 1-2 Laubblatt-Paare gebracht.

Wahrscheinlich findet sich also die angegebene Sprossbildung bei allen Arten der Untergattungen Chaenorrhinum und Linariastrum D.C. Dagegen ist sie bei der Untergattung Cymbalaria, meines Wissens, noch nicht beobachtet worden.

Unter den wildwachsenden Pflanzen, deren junge Brut man selten in der freien Natur findet, und welche sich dessenungeachtet sehr leicht aus Samen ziehen lassen, nimmt die Gattung Salix eine hervorragende Stelle ein.

Mit Ausnahme der S. Caprea L. sind Keimpflanzen der Salix-Arten äusserst selten anzutreffen. Der Grund liegt nicht in mangelhafter Samenbildung, denn, abgesehen von der Mehrzahl der Bastarde, tragen die Weiden in der Regel alle Jahre reichlich keimfähigen Samen. Es beruht die Erscheinung vielmehr darauf, dass die Keimfähigkeit des Samens von sehr kurzer Dauer ist, und dass die nothwendigen Bedingungen für die Einleitung und Durchführung des Keimungs-Processes selten zusammentreffen.

Wichura (Flora 1854. p. 1, und Verhandl. der schles. vaterl. Gesellschaft 1856. p. 56.) hat bereits darauf aufmerksam gemacht, dass, wenn der Weiden-Same gleich nach dem Austreten aus der Kapsel auf feuchten Boden ausgesäet wird, er schon nach 12 Stunden die ihn umhüllende zarte Haut abstreift, die Keimblätter entfaltet und seine Wurzel in die Erde bohrt. Lässt man den Samen auch nur ein Paar Tage alt werden, so braucht er sehon etwas länger um zu keimen, 
und wenn er 10-12 Tage an einem trockenen Orto gelegen, hat er die Keimkraft gänzlich verloren.

Der Same muss also gleich nach dem Ausfallen auf einen, von sonstiger Vegetation entblössten Boden zu liegen kommen, welcher entweder schon feucht ist, oder doch bald befeuchtet wird, - Verhältnisse, welche in der freien Natur nicht leich t geboten werden.

Nur einmal erinnere ich mich, einen solchen Fall beobachtet zu haben. In der Umgegend Breslau's führt ein wenig befahrener Weg über sandigen Boden mit lehmigem Untergrunde durch ein Weidengebüsch. Als ich diesen Weg an einem sonnigen Vormittage, Mitte Mai, passirte, hob die leicht bewegte Luft den Samen der Weidensträucher aus den Kapseln und streute ihn überall umher, ohne ihn weit fortzuführen. Des Nachmittags trat ein mehrstündiger SprühRegen ein, und als ich nach einigen Tagen denselben Weg aufsuchte, fand ich den ganzen Boden, namentlich die Wagengeleise mit unzähligen Weiden-Keimlingen bedeckt, welche sich auch, wo sie nicht durch Fuhrwerke oder Fussgänger zerstört wurden, bis gegen den Herbst hin kräftig weiter entwickelten.

Hier waren also die nothwendigen Bedingungen eingetreten. Der Same hatte sich bei länger anhaltendem schönen Wetter vollständig ausbilden können, war bald, nachdem er auf den vegetationsfreien Boden gefallen', hinreichend nass geworden, und hatte auch, bei dem lehmigen Untergrunde längere Zeit die unentbehrliche Feuchtigkeit behalten, um sich gehörig auszubilden.

Hieraus erklärt sich zugleich, weshalb man gerade von der S. Caprea L. überall in Gebirgsgegenden Keimlinge findet. Der Same wird durch den Luftzug gegen feuchte Wegeränder, in schattige Felsspalten oder auf bemooste Felsstücke getrieben, keimt und wächst, je nachdem er die nöthige Nahrung findet, mehr oder weniger kräftig fort. Oft stehen noch im August und September, namentlich auf feuchten Felsen, junge Pflanzen der S. Caprea, welche ausser den beiden Keimblättern erst ein einziges, höchstens zweei kleine Laubblätter hervorgebracht haben, weil es ihnen dort eben an Nahrung fehlte, während Exemplare in besserem Boden 6-8 Laubblätter in ortschreitender Grösse, fast bis zur normalmässigen zeigen. 
Diese haben indessen die Keimblätter gewöhnlich schon abgeworfen.

Man würde sich täuschen, wenn man annähme, dass die dürftigen Exemplare erst später, nachträglich, gekeimt hätten. Auch bei ihnen besitzt der Stengel schon eine ziemliche Consistenz, wogegen er bei wirklich jungen Keimlingen von gleicher Grösse, noch vollkommen krautig ist.

Um mich selbst von dem Keimungsprocesse bei den Weiden zu überzeugen, nahm ich Mitte Mai 1875, des Mittags, Samen der S. cinerea L., welcher eben aus den Kapseln trat, und legte ihn zu Hause auf einen Topf mit sandiger Erde, so dass ein Theil desselben leicht mit Boden bedeckt, ein anderer Theil frei lag, und besprengte das Ganze. Die unscheinlichen graugrünen Körner schienen mir nicht gerade keimfähig zu sein. Indessen wagte ich den Versuch.

Gegen Abend zeigten sich die unbedeckt gebliebenen Körner aufgedunsen und stärker grün gefärbt. Grund mehr für meine Befürchtung, dass der Samen unreif zusammengeschrumpft und nur durch die Feuchtigkeit wieder aufgequollen sei.

Indessen waren am nächsten Morgen auch die mit Erde bedeckt gewesenen an die Oberfläche gekommen und sämmtlich stark angeschwollen. Gegen Mittag konnte man schon durch die sehr dünne Samenhaut die Keimblatt-Spalte schimmern sehen, und bis gegen Abend waren die Häutchen geplatzt und die Keimblätter auseinander gegangen. (Ein einziges Körnchen, welches vielleicht tiefer gelegen, kam erst 24 Stunden nach den übrigen an die Oberfläche.) ${ }^{\circ}$

Der ganze Vorgang des Keimens hatte also circa 28

- Stunden gewährt, und war in seinem Anfange (dem Anschwellen der Körner) schon nach 6 Stunden wahrzunehmen.

Von nun an schritt aber die Entwickelung ein wenig - langsamer fort, so dass bis Ende Juni die kräftigsten Exemplare nur fünf Laubblätter, bei etwa $5 \mathrm{Cm}$. Höhe, hatten. Weiter konnte ich die Beobachtung, wegen einer längeren Abwesenheit von Hause, nicht fortsetzen. Nach Wichura's Angabe sollen die Keimpflanzen der Weiden aber bis zum Schlusse der Vegetations-Periode gegen $40 \mathrm{Cm}$. und darüber hoch werden.

Meine Untersuchungen stimmen mit denen Wichura's 
was diə Zeitdauer betrifft, nicht genau überein; doch können aussere Umstände die Verschiedenheit herbeigeführt haben.

Leider war ich im folgenden Jahre (1876) nicht im Stande, die Beobachtungen auf andere Species und auf die Dauer der Keimfähigkeit auszudehnen, weil das kalte trübe Wetter in den Monaten April und Mai die Entwickelung der Blüthe gestört hatte, und keimfähiger Samen nicht ausgebildet worden war. 